OPEN ACCESS

Edited by:

Angelos Mouzakitis,

University of Crete, Greece

Reviewed by:

Stephen Turner

University of South Florida,

United States

William Outhwaite,

Newcastle University,

United Kingdom

${ }^{*}$ Correspondence:

Lawrence Hamilton Williams

lawrence.williams@mail.utoronto.ca

Specialty section:

This article was submitted

to Sociological Theory,

a section of the journal

Frontiers in Sociology

Received: 29 May 2017

Accepted: 17 August 2017

Published: 04 September 2017

Citation:

Williams LH (2017) From Conscious

Values to Tacit Beliefs: Assessing

Parsons' Influence on

Contemporary Sociology.

Front. Sociol. 2:10.

doi: 10.3389/fsoc.2017.00010

\section{From Conscious Values to Tacit Beliefs: Assessing Parsons' Influence on Contemporary Sociology}

\author{
Lawrence Hamilton Williams* \\ Sociology, University of Toronto, Toronto, ON, Canada
}

Much sociological research is now focused on demonstrating how culture both motivates individuals to act and provides them with justifications for their actions (Vaisey, 2009). However, I argue that this sociological work relies on a model of action that sees culture itself as driving action beyond individuals' reflexive use of culture. I argue that it does so by conceptualizing the internalization of culture as pre-subjective and impersonal, essentially committing what is often deemed the Parsonian problem of diminishing the contingent nature of social action through the use of abstractions. Just as Parsons was charged with placing undue emphasis on various social systems rather than on persons, dominant strands of sociological inquiry overemphasize the salience of shared norms and schemas at the cost of individual perception. The major difference, however, is that while Parsons justified his focus on the system level by framing individuals as highly conscious and deliberate in their actions, contemporary sociologists tend to frame individuals' actions as largely unconscious and reliant on situational logics. In doing so, the consciously and normatively overdetermined actor in Parsonian sociology is now unconsciously and situationally overdetermined in contemporary sociology, a perspective ironically anticipated and deliberately positioned against by Parsons himself. Thus, I assert that efforts to de-Parsonize the discipline have given rise to theoretical problems that need resolution. I demonstrate how utilizing some of Parsons' key insights on the importance of simultaneously considering multiple levels of analysis when studying action could be a fruitful way to proceed.

Keywords: dual-process model, culture, Parsons, Weber, action, reflexivity

\section{INTRODUCTION}

How should culture's impact on action be conceived? Brought to the fore by Parsons' interpretation of Weber's theory of social action, this question has traditionally been addressed in two ways: culture is seen as providing the ends or ultimate concerns to which actors orient their actions; or culture is seen as providing the means or habits, styles, skills, and understandings that individuals use to navigate their way through the world, leaving the ends or goals of one's actions ultimately left up to the individual herself. While this latter view has been popular in sociology for at least the last 20 years, a third alternate view has been raised backed by the assertion that seeing culture strictly as means creates a rupture between motivation and meaning (Vaisey, 2009, p. 1678) and thus between culture and action. That is, as questioned by Vaisey (2009), p. 1678, if culture provides 
only problems and "tools" or solutions, and these factors are loosely coupled in that individuals can use multiple tools in their responses to the same problems, then how and why does an individual choose the particular tools that they do?

To address this gap, Vaisey (2009) takes the claim that beliefs and values constitute aspects of one's repertoire (Swidler, 1986; DiMaggio, 1997) and uses it to re-frame the ways in which such tools are used in calls for action. Vaisey (2009) alters the idea that situations prompt the actor to either unconsciously or consciously deploy their tools to make sense of the situation into an alternative casting where such tools condition this very prompting independent of the situation's perceived call for action, thereby giving culture a direct link to action by shaping the very perception of the situation beyond the actor's reflexive grasp; the choice of tools used is positioned as a product of this independent rendering rather than one's own assessment of the situation. Therefore, under this reframing, this "third alternative" (Swidler, 2008, p. 616) view of culture and action holds that culture can and does independently motivate action by providing individuals with the cultural understandings that both motivate their actions beyond any form of personal assessment and provides the tools with which they may perform "post hoc justifications" of why they chose whichever action they did after the fact (Vaisey, 2009, p. 1687). Meaning now becomes central to analysis and is primarily seen not as active work performed by an actor when prompted by a situation and its call for action (Swidler, 2003), but as held deeply within the individual's internalized cultural repertoire, pushing the actor into situations, responding using tight logics for action which lie beyond her awareness, and thus shaping action from the inside out (Lizardo et al., 2016).

While this third view rightfully foregrounds the role of motivation in shaping action, I argue that by seeing motivation as residing primarily within cultural repertoires or cultural "elements" (Lizardo et al., 2016, p. 293), it has only captured part of the culture-action nexus. That is, the motivation to act must be seen as dependent on external culture in the opportunities for action it presents in conjunction with one's cultural affordances, which are selectively used to make sense of such situations (ElderVass, 2010; Decoteau, 2016; Lizardo et al., 2016). By placing motivation primarily within the individual's repertoire, I hold that sociologists by using this view are promoting a misleading view of culture and action harking back to the "Parsonian" culture as ends model (Lizardo et al., 2016, p. 298), where ideas reigned supreme as the "unmoved mover in the theory of action" (Swidler, 1986, p. 274). The major difference, however, is that while Parsons justified his focus on the system level by framing individuals as highly conscious and deliberate yet highly normative in their actions (Lizardo et al., 2016, p. 294), contemporary sociologists tend to frame action as largely unconscious and reliant on situational logics rather than shared norms. In doing so, the highly conscious yet paradoxically unreflexive, normatively overdetermined actor in Parsonian sociology (Joas and Knöbl, 2013) is now unconsciously and situationally overdetermined in contemporary sociology (Archer and Elder-Vass, 2012; Akram, 2013). This new view, ironically, is anticipated and deliberately positioned against by Parsons himself.

\section{CULTURE AS MEANS, ENDS, OR BOTH?}

In Economy and Society (1968), Weber put forth a theory of action whereby individuals act according to their perceived interests and which ultimately contributed to the lineage of the voluntaristic theory of action traced by Parsons (Holton and Turner, 1986; Silver, 2011). What marked Weber as distinct in this line of theorizing was his insertion of the actor's subjectivity by way of ideas into his analysis, giving his theory its widely perceived “idealist" label (Parsons, 1949, p. 12). Such idealism was made evident by Weber's (Weber, 1968) assertion that beyond merely acting toward one's own self-interests, the interests individuals act toward could broadly be reduced to ideal types of interest based on the particular type of subjective meaning attributed to a particular situation by the individual (Cohen et al., 1975; Lee and Munch, 1979). These types were the following: value rationality whereby the actor acted with the intention of fulfilling an end or goal that he or she self-consciously desires; instrumental rationality whereby the actor felt they needed to perform the action as a means to some end goal; affectual action whereby the actor acted due to their impulses or feelings; and traditional action that was the product of deeply ingrained routines or habits (Weber, 1968, p. 24-25). Weber (1968) claimed that the meaning one sees in a situation could be viewed through one or more of these ideal typical lenses, therefore making action relatively unpredictable and difficult to determine insofar as individuals read into situations based on just which of these "spheres" (Oakes, 2003, p. 27) or types is used to make sense of them. Individuals in this view thus act of their own accord, but in socially patterned ways based on how they frame or are cued to see a situation in terms of its meaning, as such allowing the sociologist to probe into how and why these readings both exist and occur as they do (Gerhardt, 2011, p. 21). As such, Weber's own work, while often framed as idealist, could be seen as more institutional (Collins, 1980, 1986) and in line with recent developments in sociological thought on the structured and situated (Haraway, 1988, p. 575) nature of individual action.

While Weber (1968), p. 26, placed no particular emphasis on any of these ideal types of action as he saw that each was used in varying degrees depending on the contingencies present in an individual's life, Parsons saw all of these forms of action and interest as being reducible to one's understanding of social norms (Parsons, 1949, Cohen et al., 1975; Alexander, 1983). Such a claim could be made because Parsons (1949) held that such norms hold the ultimate rationales behind why these actions are and should be performed, thus making action in all of these "spheres" ultimately value rational in that all action can be seen as working toward the ends posited by one's culture rather than merely to specific personal or even ideal typical motivations for action such as doing something routinely or instrumentally (Cohen et al., 1975, p. 231). That is, Parsons claimed that since all of one's actions require understanding what such actions are and why they matter collectively, they are thus rooted in normative understandings of the world which furthermore provide the very interests according to which these apparently different rationales lie (Burger, 1977; Turner, 1991). Thus, such ideal types of social action are integrated at a deeper, collective, normative level, therefore making each one different only at the level of particular 
qualitative meaning experienced by the individual (Parsons, 1949, p. 76). Such a view is clearly expressed in the following statements by Parsons (1949): first, that:

The logical starting point for analysis of the role of normative elements in human action is the fact of experience that men not only respond to stimuli but in some sense try to conform their action to patterns which are... deemed desirable' (Parsons, 1949, p. 76).

And second, because this normative element is present in all action, that "all action must be seen as effort to conform with norms" (Parsons, 1949, p. 76-77), a claim that can only be read as asserting the presence of normative understanding in all readings of social life and as such giving it its central location in action.

Thus, by using this framing of Weber's theory of social action, Parsons believed that he could extend the contingent, situational theory of action crafted by Weber, whereby situations prompt individuals to act based on an array of potential logics and framings, into a general theory of action whereby the sociologist could predict action based on the social norms present in a society (Cohen et al., 1975; Wagner and Zipprian, 1986; Turner, 1991; Oakes, 2003). That is, the level of analysis could be taken one step higher, sidestepping such variations in action to getting at a deeper source: how culture provides the very fabric from which such variants are made in the form of integrative norms as opposed to discrete spheres of action which varied in their presence in action based on historical contingencies. This further connects to Parsons' "convergence thesis" (Holmwood, 2014, p. 39), whereby issues in both utilitarian and value-oriented approaches to the study of action are reconciled through a synthesis of Marshall's, Pareto's, Durkheim's, and Weber's own emergent ideas of voluntaristic action. By synthesizing rational and valuative dimensions of action within a total social system as he saw it emerging in the works of these thinkers, Parsons believed that he could solve issues of emphasis inherent in both types of account.

In engaging in this synthetic work, however, Parsons has been criticized for being overly abstract and devoid of empirical referents (Mills, 1959; Holmwood, 2014). Mills' (Mills, 1959, p. 42) critique of Parsons, for example, focused on how his emphasis on values minimized his program's ability to study concrete social phenomena-namely, institutions. Similarly, Holton and Turner (2015), p. 5, state that Parsons' emphasis on mapping out the valuative qualities of individuals' decisions and actions rather than focusing on the kinds of structural inequalities that sociologists such as Mills (1959) were concerned with caused him to be charged with committing conservative, bourgeois sociology.

Importantly, Parsons' own work need not be interpreted as leading to this sort of search for deeper, latent, systemic causes of action at the cost of empirical depth (Alexander, 2014; Holton and Turner, 2015). For example, Gerhardt (2011), p. 33, discusses how far from being averse to social change or to empirical work more broadly, Parsons' deep concern with democracy and modernity anchored his work in the study of social problems. Part of Parsons' emphasis on "grand" theory and, indeed, arguably his main motivation in writing The Structure of Social Action (1949) was his intention of bringing systematic analysis to the study of democratic and other social problems touched on by thinkers in a variety of disciplines but not yet united via common themes. In synthesizing such work, Parsons believed that he could foreground shared insights into the human condition while establishing sociology as a "systematic social science" (Gerhardt, 2011, p. viii). Far from being deeply driven by abstraction, Parsons' work even sought to fortify lines of research, which focused on more interpretive dimensions of the human experience. In doing so, Parsons' work should not be seen as promoting purely voluntaristic individual action on the one hand or analysis simultaneously determined and determining structures on the other, but as being an "action systems theory" (Turner, 1991, p. xvi). Again, the intention behind this was dual: clearer understanding of contemporary social problems and the unification of lines of research that were diverging despite their parallels (Parsons, 1949, 1991).

\section{Culture As Means for Action: The "Tool Kit" or Repertoire View of Culture}

While the dominant reading of Parsons (Swidler, 1986; Gerhardt, 2011) frames him as interpreting Weber's theory of social action in such a way as to assert that culture always provides individuals with their ultimate concerns and thus the ends of their action, many sociologists critiqued this notion by claiming that Weber viewed ultimate concerns as causing behavior-thus constituting the ends of action-only on particular occasions, with culture merely providing the means for action the bulk of the time (Cohen et al., 1975; Lee and Munch, 1979; Swidler, 1986). That is, re-readings of Weber's work led many sociologists to conclude that Weber was actually presenting a much looser coupling of culture and action, whereby cultures provide individuals with both the habits, skills, styles and general understandings to make sense of situations as well as the demands for action needed to prompt such reflexive inquiry, while on rare occasions providing them with tighter, less debatable, or interpretable logics for action based on particular religious ideologies (Swidler, 1986). While this latter assertion came under fire due to it providing a view of social life where ideas motivate action outside of the contexts that prompt actors to make sense of a situation (Swidler, 1986), Weber's otherwise situational or interest-based focus resurfaced in reinterpretations of his work. Such re-casting or "de-Parsonizing" of Weber's approach (Cohen et al., 1975, p. 229) to social inquiry is captured well by Swidler's (Swidler, 1986) piece Culture in Action, which also provides an explicit critique of Weber's treatment of ideas to, I argue, get rid of Weber's theory of the seeds which prompted Parsons' deterministic interpretation of it and, as will be demonstrated later in the article, the interpretations of other sociologists who implicitly subscribe to the culture as ends view.

In Culture in Action (1986), Ann Swidler begins by questioning just what role ideas or culture, more broadly, play(s) in shaping action. In opposition to the culture as ends view provided unconditionally by Parsons and conditionally by Weber, she asserts that "[c]ulture influences action not by providing the ultimate values toward which action is oriented, but by shaping a repertoire or 'tool kit' of habits, skills, and styles from which people construct 'strategies of action"' (Swidler, 1986, p. 273). That is, culture strictly provides the means for action rather than its ends, leaving the 
latter up to the individual herself. This is because culture provides the individual with problems as well as the understandings to view and address such matters, but cannot control precisely how or why one goes about this business (Swidler, 1986, p. 275). Such a strong claim for this view of culture's role in action is supported by her own counter example of when culture does indeed appear to provide the ends of action for individuals, what she terms "unsettled times" such as the times of "high ideology" in which Weber saw religious ideas as pushing action the way it did (Swidler, 1986, p. 278).

In such unsettled or highly ideological times, individuals at first feel at a loss as to how to organize their action-they either lack clear end goals for the cultural equipment that they already possess or have lost the capacity to live out an end to which they once were content with working toward. For example, an individual who lost the spouse that they had been married to for several years, along with the friendships and children that came along with their union with this individual, may feel that the habits, skills, and styles-such as routinely waking up to the sound of a screaming child, kissing their partner goodnight, going for runs with their neighbors-no longer constitute the means for stable or expected living as they once did due to the individual's lack of ability to carry out these actions. Thus, this situation opens up two potential scenarios. In the first scenario, this loss may lead the individual to seek out a new end goal, which will bring about new habits, skills, and styles and thus replace these now no longer functional or even performable ones (Swidler, 2003, p. 77). If, however, the individual does not embark on such an "upstream identity quest" whereby she drops all of her tools in search of new ones aimed at a "better life" (Swidler, 2003, 2008), then she may enter into the second scenario where she may try to find new ways to frame these "tools" and thus use the elements of her repertoire for some new end, a phenomenon known as "satisficing" or making the most of one's means (Lizardo and Strand, 2010). Regardless of whether the individual swims upstream under the hopes of starting a new life or simply "satisfices" and makes the most of her means, in both situations, the active work remains the same: searching for new goals or ends of action within one's culture.

\section{Culture As the Ends of and Means for Action}

While repertoire theorists (Swidler, 1986, 2003; Lamont, 1992; DiMaggio, 1997) assert that culture strictly provides one with the means for action, leaving one's goals and motivations up to how they perceive the demands they are faced with throughout their lives, the role of such tools or repertoires is contested by sociologists. The core of the debate surrounding these tools lies in regards to the ontological status or level of cohesiveness of such assemblages of cultural elements: do the elements of one's repertoire constitute dispositions capable of conditioning behavior outside of the context of scenarios, which call forth action (Vaisey, 2009)? Or do they simply make up the "kit" one uses to make decisions only when confronted with problems (Swidler, 1986, 2003). In this section, I will be focusing on the former claim toward dispositions, with Vaisey (2009) and other sociologists' both explicit and implicit claims that culture sediments into lines of action held within the individual's unconscious, which inform one's decision-making prior to their reflexive analysis of the situation. That is, this camp asserts that reflexivity or the selection of tools is indeed "post hoc justification," as such a capacity is merely the froth on top of deep-seated calculations and motivations, which have been placed within the individual by way of direct, practical, unconsciously filtered and thus purely social, worldly experience.

\section{Vaisey and the Dual-Process View of Culture}

In his Motivation and Justification (2009), Vaisey asserts that sociologists of culture tend to pick and choose between seeing action as motivated by one's values and beliefs and seeing action as prompted by situational demands. These different views of culture's causal influence, he claims, are due to sociologists overemphasizing either situations or actors' meanings, neglecting a proper balance of the two in explanations of action (Vaisey, 2009, p. 1676). Regarding the tendency to focus on situations, Vaisey (2009), p. 1677-1678, claims that there is a rupture between motivation and meaning inherent in the widely popular repertoire approach in sociology, as he asserts that this view places too much causal power in situational demands as it sees personally held motivations in the form of values and beliefs as merely "post hoc justifications" for actions individuals take with the real "drivers" being institutional demands on the actor. The solution that Vaisey (2009), p. 1679, proposes is a "dual-process" view of culture, where the repertoire of information that culture provides the individual can be seen as an unconsciously held driver of action, which can, on occasion, be steered and trained by the conscious individual. As such, Vaisey (2009), p. 1705, claims that by viewing culture as possessing this dual function-providing deep-seated, unconscious motivations for actions, along with the tools required to be able to reflect post hoc on why an individual acted the way they did and those capable of "re-routing" their future actions-meaning can be accurately captured in sociological analysis.

Indeed, despite criticisms of the utility of the dual-process model (Leschziner and Green, 2013), this model has become increasingly used by sociologists who are intent on bridging macro and micro levels of analysis (Lizardo et al., 2016). Moreover, in light of criticisms such as those made by Leschziner and Green (2013) and Williams (2016b) regarding the difficulty of categorizing individuals' experiences as either unconscious or conscious, Lizardo et al. (2016), p. 298, assert that the very utility of this model lies in its capacity to correctly frame thought and action as being either unconscious or conscious. As such, rather than critique, the dual-process model as a whole, Lizardo et al. (2016), p. 298, suggest that this model be seen as broad, umbrella framework that can be applied to myriad empirical problems.

\section{Can Culture Be Both Means and Ends?}

While this dual-process view of culture and action may appear to provide an account that captures both the ways in which culture unconsciously influences action and how actors are able to 
"override" such conditioning effects (Vaisey, 2009, p. 1687-1703), I argue that this portrayal of culture does so by assuming that internalized culture can filter perception in clearly demarcated, tight, and domain-specific ways. That is, the idea that one can be largely driven by their repertoire requires that situations cue or trigger particular cultural understandings or tools rather than others in patterned ways, thus enabling an individual to possess various dispositions for action outside of their reflexive or conscious grasp (Archer, 2003, p. 5-7). Such a claim then presents a tight coupling of culture and action, whereby rather than seeing situations as giving rise to reflexive assessment, which then brings forth cultural understandings based on how the situation happened to be perceived (Archer, 2003, p. 13), one's accumulated stock of knowledge comes to define the very world one sees. Actions then become "unit acts" (Swidler, 1986, p. 276) assessed not by their relation to a larger "strategy of action," but by tight definitions accumulated through cultural experience.

The question this tight coupling raises, then, is if situations can bypass the reflexivity of the individual which gives rise to the inherently innovative and situational choice of tools or understandings employed, then how and why do individuals differ in the logics they bring to bear on situations? The answer to this question, as asserted by Vaisey (2009) quite clearly, lies in his understanding that such variation exists due to individuals internalizing different beliefs and values, which then unconsciously guide the choice beyond their reflexive capacity. That is, in this view, decision-making comes to be offloaded to one's mental faculties by way of the automatic "hot' and 'fast' (not deliberative) 'choices"' that our intuition makes for us based on the prior experiences we have had, but in loose and inferential ways as an unconscious system (Lizardo and Strand, 2010, p. 214). Thus, Vaisey's (Vaisey, 2009), p. 1685-1686, claim that culture can motivate action without being explicitly known by the actor appears not to reduce experience to tight unit acts by seeing experiences as "connected," yet, his idea that such sets of intuitions are based off specific beliefs and values in the form of "moral schemas" tells another story: the internalization of a particular logic marks the generation of an open system, yet one which ultimately regresses to the overarching logic of this "system," found in the initial idea that prompted it. For example, through survey data he had collected from teenagers, Vaisey (2009) found that moral views instilled early in these individuals had more of an impact on future deviant behavior in these individuals than more typically used variables like household income or family structure. While these individuals answered questions in similar ways, their different moral views appeared to unconsciously guide their life decisions, thereby making this hypothesis seem valid (Vaisey, 2009, p. 1705). Thus, by using this information, the claim that particular, tightly internalized beliefs and values can mark the trajectory of loose yet patterned life trajectories and behaviors appears to be founded, making action appear to be reducible to larger strategic assemblages, yet ones fitting the logic of deepseated cultural values rather than that seen by the actor. Further, such a tight-yet-loose view of culture and action also fits with recent work in psychology as well as a long line of sociology that has argued for the routine nature of action by seeing microlevel or individual-level behavior as genuinely creative and innovative, but derivative of cultural meanings at its deepest level (Dewey, 1922; Bargh, 1992; Joas, 1996).

I will now demonstrate how this view, along with the branches of psychology and sociology which support it, rely on the assumption that ideas have the capacity to independently motivate action. Such an assumption, I argue, thus requires positioning ideas as internalized pre-reflexively or directly by the individual, and thus fundamentally as social endowments that work beyond the actor's reflexive grasp. In this view, culture is therefore seen as driving action from the inside out, entailing the need to rid social theory of the active agent capable of using her tools as capacities rather than being used by them in a dispositional way. As such, while utilized to bring meaning back to a "de-Parsonized" view of Weber's insights about culture and action (Cohen et al., 1975), this view relies precisely on the aspects of the Parsonian scheme that it criticizes most: assumptions of value consensus and overdetermined action. However, while Parsons (1949), p. 96, emphasized how values took salience in particular situations for individuals and were a necessary phenomenon to consider to understand why individuals did not cheat and perform other "rational" antisocial behaviors more often than is the case, this new "de-Parsonized" view prioritizes value at the cost of any sense of contingency (Williams, 2016b, p. 2). While Parsonian sociology may be charged with minimizing reflexivity and individuals' personalities when assessing both action and structure (Holton and Turner, 2015), it at least intends to open up research that takes these factors more seriously (Joas and Knöbl, 2013, p. 78). Conversely, users of the dual-process model and other models that emphasize values in action close off personal qualities of action by shifting attention away from personal motive and onto shared motivations for action (Vaisey, 2009; Williams, 2016b, p. 1).

This emphasis, I argue, can-perhaps paradoxically given his emphasis on located action-be traced back to the work of Pierre Bourdieu. His research on the dispositional qualities of thought and action signaled a shift in sociological inquiry from largely situational, contingent action to tacitly motivated, typified action (Archer, 2007) and was continued by proponents of the dualprocess model in efforts to bring values back into center stage. However, rather than systematically assessing where and why such values emerge, I assert that these researchers minimize the systematic linkages between value spheres (Weber, 1968; Oakes, 2003) that were key in Parsons' approach to values. In other words, just as Parsons (1949) critiqued Weber for minimizing connections between different ideal types of action, I believe contemporary researchers who draw on Bourdieu's insights about the situated yet dispositional nature of action tend to focus on contextual specifics at the cost of broader understandings of how and why certain behavioral patterns come to the fore and recede as they do throughout the social world.

\section{How the "Habitus" Implies Seeing Ideas As Independently Shaping Action}

Recently, Lizardo and Strand (2010) published an article discussing the ways in which practice theories can be divided into streams based on how much weight they place on the process of socialization. With "toolkit" theorists placing weak emphasis on 
this aspect of life and theorists subscribing to the Bourdieusian branch of practice theory- "strong practice theorists"-placing stronger emphasis on this aspect, it was deduced that these two variants of practice theory conceptualize the "imprints" of experience quite differently (Lizardo and Strand, 2010, p. 204-209). That is, repertoire theorists are steadfast in their claim that cultural elements can never come to work as the source of action (Swidler, 1986, p. 274), while strong practice theorists argue that they can, and that they do so by way of unconsciously held beliefs and values which constitute the bases off which one's reflections are made (Vaisey, 2009; Lizardo and Strand, 2010). In the stronger view, then, the view held by Parsons, Weber (conditionally), and Vaisey that ideas can indeed independently shape one's actions pre-reflexively, that is prior to the actor's involvement in the decision-making process, is made clear and argued for using the notion that practical experiences sediment into dispositions in ways without our awareness and thus should be capable of motivating action also without this awareness (Vaisey, 2009; Lizardo and Strand, 2010). Culture then gets a direct link to action as a pusher of action, with the individual being merely the "rider" of this unconscious mass of cultural logics, which has sedimented into a coercive "elephant" (Haidt, 2001, p. 820; Vaisey, 2009, p. 1683), which for the most part goes where it pleases. The image of the "cultural dope" who is the passive recipient of culture's predefined ends of action (Archer, 2003, p. 78), then, comes back to the fore, as culture takes now front, center, and back of stage in the action nexus, leaving no room for the individual's reflexive capacities to actually impact the culture it internalizes or construct lines of action in relation to larger "strategies."

While never made explicit in Bourdieu's (Bourdieu, 1984, 1990) own treatment and definition of the concept habitus, I argue that this view of culture as driving action or culture as ends is inherent in this concept, despite the fact that, just as was the case for Weber's theory of social action, it left room for seeing a loose connection between culture and action.

\section{Habitus: A Dynamic or Regressive Filter?}

While Bourdieu (1977) defined the habitus from many angles, I believe the following definition provides a general summary:

\begin{abstract}
The system of lasting, transposable dispositions which, integrating past experiences, functions at every moment as a matrix of perceptions, appreciations, and actions and makes possible the achievement of infinitely diversified tasks, thanks to analogical transfer schemes permitting the solution of similarly shaped problems' (Bourdieu, 1977, p. 95, emphasis added).
\end{abstract}

To Bourdieu (1977), then, the habitus is the cultural endowment, or "tool," provided by one's culture, which enables individuals to perceive the world around them. However, this is an inherently stratified endowment due to just how it is given to the individual. That is, one's faculties for perception are mutually constituted by their biology and their culture by way of the habitus, in that one's experiences sediment into mental structures, which now come to guide perception (Bourdieu, 1984, p. 3-78). This occurs largely by way of such cultural-biological structures generating "practical metaphors" (Bourdieu, 1984, p. 173) for action, enabling one type of action to lead seamlessly to another. For example, learning that one can communicate through speech with the individual that happens to be their mother and then extending this act to communicate with another individual. Such action is practical at this stage due to the precise logics behind how and why such communication occurs not needing to be realized by the actor, who is merely disposed to this type of behavior due to it having actually functioned well for them in the past (Bourdieu, 1984, p. 172-173), but who also depends on the "schemes" it generates unequally based on just which experiences have been grafted into it.

By using this notion of practical logic, Bourdieu extends the concept of habitus into various domain-specific ideal types, such as "working class habitus" and even more recent usages like "racialized habitus" (Bourgois and Schonberg, 2009), capturing this element of practical metaphorical generation and transposability where inner structural logics inform one's actions and decisions at a practical level despite their cultural origin. Individuals with a "racialized habitus," for example, may view their opportunities a particular way based on their particular experiences, which have sedimented into "natural" viewings of their world, which someone with a "working class habitus" may not, due to their possession of a different repertoire of meanings and practical logics. Further, fitting with the loose logic framing of culture and action seen in repertoire theories, an individual can bring a disposition to bear on a situation in novel ways by using one's disposition toward action in one area of life unconsciously in another, thus making the habitus "flexible" and "dynamic" (Lizardo, 2004, p. 393) rather than seeing such dispositions as merely driving action.

While habitus at the level of accumulated practical logics appears to capture well what repertoire theorists call habits, skills, and styles well, in that this conceptualization explicitly groups these unstructured tools into dispositions for action-for example, a "working class" disposition or habitus being composed of one's daily habits, clothing style, and work skill-where the logic of the habitus differs greatly from that of the "culture as tools" logic (Vaisey, 2009, p. 1679) lies within how such cultural endowments are perceived to be acquired. While repertoire theory rests on the premise that such tools exist only in relation to a reflexive agent capable of using these tools (Swidler, 1986, p. 276), Bourdieu's habitus carries the implication that one's very subjectivity or sense of self is constituted by such cultural capacities. That is, while a habitus may be viewed simply as a generative conceptual scheme based on one's experiences, due to the assertion that this type of scheme is pre-reflexively formed (Archer, 2010, p. 287), the idea is made that culture gets into the individual directly, therefore not positioning such capacities as in relation to such a sense of self, and as such either leaving it entirely out of the picture or viewing it is as constituted by these very capacities.

\section{Bourdieu's Affinity with George H. Mead and Their Paired Dismissal of Subjectivity}

While no definitive answers lie in his work, I assert that Bourdieu's use of the habitus assumes a socially constructed self due to this theory's affinities with George H. Mead's view of the formation of 
the self. Such affinities lie precisely in these thinkers' shared view that culture enters into the individual pre-reflexively, thereby shaping one's perception prior to their formation of a reflecting self or "user" of cultural tools.

In his Mind, Self and Society (Mead, 1934, p. 154), Mead asserts that society enters into the individual by way of rules constituting normative action, that is, by way of the generalized other, which is the individual's rendering of society or "the attitude of the whole society." Such internalization of society is seen as occurring after the individual has acquired language, as to reflect on such social meanings one has to be able to communicate intersubjectively-indeed demonstrated by his idea that only with games does a true self-concept emerge, while play merely allows the individual to perform new activities - with language being both the vehicle and the capacity to do so (Mead, 1934, p. 135-154). Thus, Mead positions this process as one in which the individual's self-consciousness is literally the capacity to see one's self through the eyes of society and thus be aware of the social codes that individuals will bring to bear on their assessments of that individual.

Such a view, then, places the self as coming into existence after knowledge of society, thus leaving reflection, itself reliant on a self off which to reflect (Mead, 1934, p. 135), to be an act that comes after culture has already sedimented into one's perception in a direct, unmediated way. Reflection thus plays no role in forming one's initial perceptions, leaving these beyond the actor's reflexive grasp and as "natural" components of their world view, therefore enabling them to be seen as "unit acts" with clear social meanings as opposed to actively positioned meanings in relation to particular strategies influencing the actor's perception. Despite Mead's (Mead, 1934) explicit theory of spontaneity by way of the concept of "I," or the non-determined aspect of the self whose actions cannot be predicted (Williams, 2016a, p. 12), by seeing the baseline of selection as occurring after language acquisition, Mead frames perception and decision-making as deeply socialized.

Put another way, if culture has direct access to one's cognitive faculties and is indeed constitutive of them, in a way only mediated by one's biology and sociospatial location in that these factors influence which culture will be directly implanted into the individual (Mead, 1934; Bourdieu, 1977, 1984; Vaisey, 2009), then the "Parsonian" notion that one's culture can provide concrete ends, free from situational constraints and potential renderings, that is that it can provide tight logics (Geertz, 1973; Swidler, 1986, p. 278) for action, should also hold. This is because, I argue, the only way that the culture as ends view can be seen as empirically tenable is if culture can bypass reflection by constituting the very bases off which one knowingly or unknowingly reflects, therefore being seen as natural by the individual and thus incapable of being viewed any other way (i.e., in light of an emergent strategy of action). It is only in such a positioning that culture can so tightly inform action as to constitute its ends. For Weber's Calvinist, for example, the ethos that one's work ethic was indicative of her position in heaven constituted the way of life for these types of individuals, not a particular reading of it, thus pushing action along this tight, suprasituational logic (Swidler, 1986; Weber, 1992). Had these Calvinists been able to envision another way of life, then their religion's portrayals of life would not be able to push their action the way Weber asserted that it did.

Indeed, marking the fact that this view is inherent in any reading of the habitus concept, it is precisely this culture-as-atfirst-natural idea that constitutes the very basis of Bourdieu's habitus and general theory of social reproduction: class inequalities become reproduced due to habits being felt as necessities (Bourdieu, 1984, p. 24), and thus culture as nature, therefore placing culture's early entry in us as a natural and unfiltered experience. Once again, I argue this based on the fact that the habitus implies that all of one's perceptions are made possible by internalized mental structures, which exist both prior to and beyond one's reflexive capacity (Bourdieu, 1977; Lizardo, 2004; Vaisey, 2009), a fact also found in Mead's (Mead, 1934, p. 154) self theory, which posits that reflection requires having already internalized the generalized other, or society's rules, and thus acquiring dispositions prior to the capacity to reflect.

What makes this formative element of the habitus relevant to my argument is that since one's habitus, dispositions, or their generalized other are prior to this capacity for reflection, it can be viewed as guiding how and, more importantly, why this process works: to the ends of such structures rather than to ends chosen by the reflexive actor. That is, if my habitus supplies me with the representations that I use to make sense of stimuli I encounter, then any reflections I make must also be done using these very prereflexive, culturally endowed representations. Since they were internalized prior to my reflexivity, then I had no part in forming them, thus leaving them purely a product of culture combined with my own physical location within my culture; since I internalized these structures directly, without reflexive interference, then they are not endowed with my own perception, that is my rendering of them in relation to a particular strategy of action or identity and thus are pure in form and hence remain distinctly cultural. Vaisey's (Vaisey, 2009) findings that moral views highly yet mostly unconsciously shape our life paths, then appears highly warranted. Following this logic as far as it takes us, an individual's actions and thoughts are personal only insofar as she can mix tight logics for action in novel ways, based on her own fallibility and "misrecognitions" (Bourdieu, 1984, p. 172) of situations, thus leaving action truly as a structure to structure relationship of mental structures with external structures (Lizardo, 2004, p. 379) or with "external cultural scaffolding" (Swidler, 1986, 2003), a point I will now address.

\section{The Personal As Froth}

While the argument I am making may seem to be antisociological, and ignorant of the fact that Bourdieu (1984), p. 173, indeed saw such "structural meanings" as being activated by situations rather than latently informing them and thus leaving them subjective insofar as they require an active agent perceiving such situations, the idea I am attempting to put forth is that the prereflexive nature of the habitus and practical knowledge in this branch of theory carries the implication that cultural meanings are purely cultural, objective, or social since they exist beyond the actor. Since they exist beyond her and are indeed beyond her "discursive" grasp (Vaisey, 2009, p. 1686), then this implies that individuals do not actually know why they do what they do, as 
the true seat of action lies within the bodily schemata that have internalized this pure, personally unmediated culture.

Such a view is indeed noted in the following claim asserted by Vaisey (2009) regarding the validity of interview data, specifically in terms of the validity of explanations individuals give about how and why they act:

Because interview methods engage with discursive consciousness alone, they cannot rule out the possibility that deeply internalized moral attractions and repulsions (grounded in schematic associations acquired through cultural experience rather than in conscious beliefs) are patterned in motivationally important ways (Vaisey, 2009, p. 1687, emphasis mine).

By using the logic laid out by Bourdieu and Mead regarding the prereflexive origins of one's cultural understandings, Vaisey (2009), p. 1687, could logically conclude that interview data merely get at the refractions of deeper collective representations, with the latter crafted not by the individual herself but by the collective (Durkheim, 1982, p. 52). Thus, the role of the sociologist becomes one of accessing culture directly by means of one's unconscious faculties, bypassing the discursive or conscious agent who is merely "misrecognizing" situations. Since Bourdieu's (Bourdieu, 1977) concept of the habitus sees only sociospatial location-one's physical placement within a society in terms of their access to cultural resources, such as work, education, and other forms of capital production-as influencing how and why an individual internalizes culture the way that they do, internalized culture remains purely cultural or supraindividual in its makeup, thus leaving reflexive assessments merely as picking and choosing between tight logics rather than as constituting such meanings due to the particular strategies of action they fit into or activate within the individual. Such logics, again, become loose only due to their inherent dynamism and flexibility (Bourdieu, 1984 , p. 101), coupled with the fallibility of the actor who may deploy an understanding in a situation not actually prompted by it, reacting rashly to my boss at work based on being consumed by a drama with a friend, for instance. While such situations may lead me to create my own meanings for things, under the premises of this theory where the origins of such thoughts are beyond my reflexive capacity and pure in state, that is as they are simply the reproduction of the institutional meaning within my mental structures (Bourdieu, 1984, p. 101), inquiring as to how and why I came to these personal conclusions brings sociology no further along as it does not address the genesis nor the dissemination of such meanings. Culture plants the seeds which I germinate due to my own confusion as to how to apply the meanings I am given, leaving the mechanisms behind this process of implanting the truly sociological source of action and my misrecognitions merely as the product of this deeper process.

\section{Must the Habitus Be Used to Reduce the Power of the Situation?}

While Bourdieu may safeguard against this "Parsonian" culture as ends interpretation due to his assertion that the structure of the habitus takes on its meaning only in relation to external culture in the form of fields (Bourdieu, 1984; Lizardo, 2004), I maintain my argument that by bypassing individual reflexivity he is still promoting a direct link between culture and action, with the habitus-field relation as a structure to structure relation (Bourdieu, 1984; Lizardo and Strand, 2010), once again leaving out the idea of the "unsocialized" or at least undersocialized individual capable of reflecting prior to the onset of their understanding of social codes or meanings. As such, without this capacity to reflect, social codes and meanings are seen as seamlessly entering the individual and as such being beyond her future reflections due to being so deeply ingrained.

Such a criticism is warranted by the very fact that Bourdieu (1984), p. 113, asserted a loose coupling between these dispositions and action in terms of the former's flexible and dynamic nature, in that the practical logics and metaphors for action which dispositions generate can be brought to bear on situations not from the same field in which these dispositions were first experienced. That is, while particular actions may be "practice turned into necessity" within the fields in which they were generated (Bourdieu, 1984, p. 101), they can be used or employed in other situations in creative ways in the same way that repertoire theorists position tools. For example, the dispositions that are responsible for a working class individual having a taste for their lot in life, while depending on unequal relations existing in their society of origin, work to provide the tools and metaphors for actions in other domains that both maintain and guarantee the utility of that taste. The innovation and creativity in individual action, then, comes not from a reflexive agent bringing personally tinged meanings to bear on situations, but by dealing with situations which cross-cut one's internalized cultural meanings and thus necessitate a "re-tooling" of one's logics to make the situation make sense, still implying a tight fit between culture and action albeit now one laced in the garb of dynamism.

As such, while Bourdieu (1984) and proponents of the habitus or enduring disposition concept (Vaisey, 2009; Lizardo and Strand, 2010) see this as inherent flexibility in the structure of the habitus, I assert that this theory places more emphasis on how early, prereflexively acquired dispositions adapt to novel situations than to how such situations actually call for and influence action, thereby producing a regressive theory of action. That is, there appears to be a contradiction between seeing one's habitus as flexible in this way and seeing culture and action as loosely coupled, harking back to the dilemma Swidler (1986) pointed out in Weber's treatment of ideas and voluntary action. If the logics individuals bring to bear when faced with problematic scenarios are contingent upon the actor's assessment of the meaning of that situation (Weber, 1968; Swidler, 1986, 2003), then precisely what will prompt an individual to read the situation through a particular habitus over another? What leads the individual to pair a disposition with an institutional demand, regardless of whether or not it actually originated in that domain?

Indeed, I believe the answer to this question lies within Bourdieu's (Bourdieu, 1984), p. 466, own work, whose claim that such structures cannot be explicitly thought about by the actor 
as they "function below the level of consciousness and language, beyond reach of introspective scrutiny or control by the will," implies a tight fit between culture and action. This claim implies that such structures unconditionally shape the processing of information when prompted with situations, thus leading one's perceptions to also unconditionally regress to the structural logics they have acquired. Any looseness of fit arises simply because one does not definitively know which structure will be shaping their perception. Thus, the question of just how and why one habitus is brought to bear when prompted to act opens up only two rather unsatisfactory options.

First, following the field logic, such choice can be seen as connected to the demands the situation makes on the actor (Bourdieu, 1984, p. 101). For example, in the context of a workplace where the individual knows they are being paid to perform services for an employer, greeting an individual whom they know is a customer may prompt a "worker's habitus" as opposed to, say, a "friend habitus" due to this awareness of the situational demands.

Second, however, and following the logic the culture as ends or culture as means and ends view, such prompting could be reduced to the habitus-level itself, in the form of "habitus-level desires" (Bourgois and Schonberg, 2009), which shape the readings of situations prior to one's reflexive assessment, and thus the realization of just which sort of dilemma they are facing. For example, my role as a video game player could lead me to view a customer in this work scenario as an individual who may play the same video games as me, thus prompting me to see her this way and ask her whether she does or not despite my knowing the workplace codes of conduct.

Thus, the availability of both the logic of institutional demands and that of personal beliefs, feelings, or moods creates a situation in which the habitus as a model for action loses ground. If indeed such mental structures were acquired prereflexively and preconsciously, thus constituting our very baselines of rational thought and biasing our decision-making in favor of these bases, then what exactly enables us to pick and choose-or have unconsciously picked and chosen for us-the particular logics we happen to use when interpreting a situation? While Vaisey (2008), p. 607, claims that repertoire theorists invest too much power in external, situational demands perceived by the actor, holding that this is promoting a "Skinnerian" stimulus-response view of social life, I believe that such demands are precisely what prompts the choice of lines of action. However, such demands do not do this by being seen one at a time as this "Skinnerian" criticism implies, but within wider strategies such as who one sees themselves as being and what they see the world as offering. These kinds of broader identities and identity projects, however, have no language in the habitus or dispositional views. As a result, I assert that they call for more nuanced focus on the interplay between individual and social structure, and as such beg for re-utilization of some of Parsons (1949) key insights in this matter-namely, his emphasis on including multiple levels of analysis in a single research project and his commitment to seeing different normative or cultural understandings as mutually constituting a shared meaning system.

\section{Attempts at Bridging Habitus and Reflexivity: The Reflexive Habitus and Reflexive Modes}

While I have focused on scholars who have either used or challenged the concept of habitus, a series of scholars have sought to refine the concept and to-implicitly and perhaps unintentionally-conduct research using Parsons (1949) keen awareness of the necessity of analyzing individual thought and action in a multivalent manner. Key in this tradition is Claire $\mathrm{L}$. Decoteau (2016), p. 303, and her concept of the reflexive habitus. Noting Archer's (Archer, 2007) claims of regression and stasis charged against the habitus, Decoteau (2016) argues that the concept can be salvaged by incorporating Archer's insights on reflexivity into its very formation. Rather than see habitus and reflexivity as antithetical, Decoteau (2016), p. 318, claims that individuals' unique positioning in multiple fields gives them myriad situational logics and understandings to interpret their worlds and, hence, endows the concept of habitus with a sense of reflexivity.

Archer critiques the reflexive habitus, however, for still committing the same fundamental error as the original concept of habitus: structural influences, mistaken as nature, are seen as forming the very bases off which one makes all reflexive assessments. Rather than attempt to salvage this concept, Archer (2007), p. 145, claims that individuals develop particular ways of engaging in reflexive assessments-reflexive "modes" - based on experiences they have early in their lives with their families. Archer (2007) states that individuals have relatively stable ways of engaging in reflexive thought. She has four key typologies: communicative reflexives, autonomous reflexives, meta reflexives, and fractured reflexives. Varying in terms of both how much the opinions of others weigh in on one's reflexive assessments as well as in terms of how successful such assessments are for action, Archer (2007) uses the typologies of communicate, autonomous, meta, and fractured reflexives to enable interpretation of how and why individuals behave as they do (Caetano, 2015).

However, Archer's (Archer, 2010) assertion that reflexive styles are learned over the life course are somewhat problematized by her previous claims regarding reflexivity's pre-reflexive nature. Indeed, Akram and Hogan (2015) and Decoteau (2016) claim that by stripping reflexivity of its socialized elements Archer's own claims about individuals' commitments to and enactment of their projects or strategies in varied ways cannot easily be made sense of. If reflexivity is a constant capacity that individuals have, why would it take on specific forms or "modes" throughout one's life course? While Archer (2010) focuses on early childhood experiences, what is to prevent later experiences from crystallizing into such modes? Questions such as these work to make Archer's (Archer, 2010) concept of reflexive mode appear both similar to reflexive habitus in so far as this concept comes to be seen as quite similar to the original formulation of habitus due to its emphasis on early lived experience in shaping one's dispositions, as well as untenable due to a lack of specification over its development for any given person. 


\section{DISCUSSION}

I believe that this puzzling quality of Archer's (Archer, 2010) work on reflexive modes, coupled with Decoteau's (Decoteau, 2016) salvaging of the concept habitus through the incorporation of reflexivity, both demonstrate an implicit commitment on the part of the authors to a "Parsonian" culture as ends view. In both instances, experiences are seen to sediment in relatively unproblematic ways within individuals as dispositions or proclivities for action. Despite attention to the apparently post-reflexive or learned aspects of these dispositions-in contrast to Bourdieu, who, as mentioned above, is charged with positioning the development of dispositions as prior to the development of an individual's reflexive capacities (Archer, 2010) - these authors still hold that, once formed, dispositions exert strong influence on individual thought and action.

While dispositions may and indeed often do greatly influence what individuals think and do (Leschziner, 2015), emphasizing the dispositional over the situational or otherwise relational elements of thought and action depersonalizes (Strauss, 2006) these phenomena. Much like for proponents of the dual-process model or the dual-process framework (Vaisey, 2009; Lizardo et al., 2016), culture is seen as seamlessly influencing individuals' cognitive and emotional capacities. Questions regarding the extent to which experiences manifest into dispositions in the form of internalized cognitive schemata (Williams, 2016b, p. 6), for instance, become relegated to the margins. As such, I assert that claims regarding the specificity of research utilizing concepts such as the habitus, the reflexive habitus, reflexive modes, and the dual-process model/ framework more broadly promote what Mills (1959) would see as both grand theory and abstract empiricism. Rather than explicitly theorizing how and why culture shapes actions, the use of these concepts enables researchers to make claims about this process that are seemingly at odds. Tensions between the reflexive habitus and reflexive modes attests to some of this issue on the one hand, while recent debates regarding the relative discreteness of automatic and deliberative cognitive faculties attest to conceptual difficulties inherent in the dual-process model/framework on the other (Leschziner and Green, 2013; Leschziner, 2015; Lizardo et al., 2016).

What the concepts and models critiqued above have in common is their shared dismissal of unified, synthetic research. Indeed, similar sentiments have been expressed by sociologists specialized in many different areas, although not addressed to what I have termed the re-Parsonization of the field of sociology. Researchers studying a wide range of topics have made calls for incorporating multiple factors when analyzing the decisions individuals make regarding important aspects of their lives, ranging from how one makes the choice to educate one's child (Lareau, 2003), to how one decides to commit crime (Vaughan, 1998), to how one chooses a particular career (Leschziner, 2015). In such calls, researchers tend to assert that there is a gap between studies which focus on broad population dynamics and those which focus on localized behavior (e.g., Lamont et al., 2014). While studying both of these issues is important, these researchers argue that there is often a tendency to construct models at each level at the cost of a richer and more holistic explanation (Morgan and
Winship, 2015). This results, they argue, not only in competing explanations but also in conceptually vague ones (Western, 1996). These researchers often assert that efforts to understand individuals' decisions need to move beyond seeing decisions as being either informed by external factors or personal choices of individuals, to more squarely situating individual decisionmaking in the contexts in which it occurs (Baldry et al., 2007).

To move further away from both grand theory and abstract empiricism, I further argue that it is both methodologically and analytically fruitful to frame the decision-making process in general as a temporal continuum marked by three distinctions based on when an individual evaluates any given matter: future-orientation-when a person is evaluating something that has yet to occur and therefore has expectations about that thing; present-orientation - when a person is evaluating something that is currently occurring in his or her life and therefore can have attitudes about that thing; and orientation toward one's past-when a person is evaluating something that has happened to them in the past and therefore can make assessments about that thing (Mische, 2014). Seeing decisions as a composite of expectations, attitudes, and assessments necessitates that sociologists take into consideration a wide range of theories that already exist in our toolkits when analyzing the decisions of any given person at any given time simultaneously. Ideas of socialization and the formation of dispositions (Bourdieu, 1984), the contingent nature of decision-making (Swidler, 1986), the dynamic nature of personal growth and identity formation (Ibarra, 1999), and the relative stability of intersubjectively shared categories such as roles (Goode, 1960; Wacquant, 1990) must all simultaneously be brought to bear on decisions as they are made by individuals to give full accounts of individuals' actions.

\section{CONCLUSION}

In this article, I have put forth the argument that culture must be viewed as providing the resources individuals use to navigate their way through the world. I argued that this view lies in direct opposition to views which assert that these resources can independently motivate one's actions by providing them with ends or ultimate concerns to which they can anchor themselves. Key in my rejection of this latter view is the idea that seeing culture as capable of providing such ends for action requires seeing these ends as capable of being viewed outside of situations, and thus in clear, uncontestable ways, as such promoting a "re-Parsonized" view of Weber's theory of action whereby culture provides both the means for and ends of action.

If the ends of action that individuals seek out in their cultures thus constitute the means through which these individuals actively construct their own identities, then what does this mean for sociologists? As opposed to the claims made by Vaisey (2009), p. 1687, that semistructured and in-depth interviews only give sociologists access to the interviewees' "discursive consciousness," therefore leaving the true drivers of action inaccessible to the sociologist, seeing identity as actively constructed by the individual and as constructing the lines of action one takes by giving them their particular meanings means that these interviews do 
not miss out on any inner drivers, but enable the sociologist to probe into the mechanisms responsible for individuals' identity claims, and thus the specific lines of action they happen to construct as part of their larger strategies or action plans (Martin, 2011; Pugh, 2013). That is, interviews allow the sociologist to see how individuals frame situations, imbuing these situations with the sort of ideal typical meaning Weber (1968), p. 26, claimed that they do, and to use this information as a springboard for probing into the institutional dilemmas to which such strategies are posed. Interviewing an "addict," for instance, could unearth information on how actors struggle to meet the demands they perceive society both provides and overwhelms them with. This would give the sociologist access to the particular rationales and strategies they use and thus enable them to see which culture the respondent brings to bear and why.

The view of culture and action I have promoted throughout thus requires more work on delineating precisely how and why individuals embark on the sort of identity quests that they do. It involves not only seeing which institutional demands trigger particular lines of actions across groups of individuals or individuals in general but also on personalizing sequences of action (Garro, 2000; Strauss, 2006). Personalization involves seeing the use of culture as closely bound to individuals' self-concepts (Leschziner, 2015 , p. 167) and their contexts of action. It necessitates use of methods that probe into the particulars of individuals' actions in ways not amenable to broad-brush generalizations and one-way causal statements (Jerolmack and Khan, 2014).

Thus, far from the "third alternative" (Swidler, 2008, p. 616) promoted by Vaisey (2009) and seen as logically stemming from "strong practice theory" (Lizardo and Strand, 2010, p. 204) with its emphasis on structure to structure relations, a truly "de-Parsonized" view of Weber's interpretive branch of sociology appears to be precisely what is demanded (Cohen et al., 1975).

\section{REFERENCES}

Akram, S. (2013). Fully unconscious and prone to habit: the characteristics of agency in the structure and agency dialectic. J. Theory Soc. Behav. 43, 45-65. doi: $10.1111 /$ jtsb. 12002

Akram, S., and Hogan, A. (2015). On reflexivity and the conduct of the self in everyday life: reflections on Bourdieu and Archer. Br. J. Sociol. 66, 606-625. doi:10.1111/1468-4446.12150

Alexander, J. C. (1983). The Modern Reconstruction of Classical Thought: Talcott Parsons. London: Routledge.

Alexander, J. C. (2014). The Modern Reconstruction of Classical Thought: Talcott Parsons. London: Routledge.

Archer, M. S. (2003). Being Human: The Problem of Agency. Cambridge: Cambridge University Press.

Archer, M. S. (2007). Making Our Way through the World: Human Reflexivity and Social Mobility. Cambridge: Cambridge University Press.

Archer, M. S. (2010). Routine, reflexivity, and realism. Sociol. Theory 28, 272-303. doi:10.1111/j.1467-9558.2010.01375.x

Archer, M. S., and Elder-Vass, D. (2012). Cultural system or norm circles? An exchange. Eur. J. Soc. Theory 15, 93-115. doi:10.1177/1368431011423592

Baldry, C., Bain, P., Taylor, P., Hyman, J., Scholarios, D., Marks, A., et al. (2007). The Meaning of Work in the New Economy. New York: Palgrave Macmillan.

Bargh, J. A. (1992). The ecology of automaticity: toward establishing the conditions needed to produce automatic processing effects. Am. J. Psychol. 105, 181-199. doi: $10.2307 / 1423027$
Utilizing recent insights from cognitive science on the nature and function of intuition is a promising route to take (Leschziner, 2015; Williams, 2016a,b). Such insights have been implicitly used in much sociological work ranging from Durkheim's (Durkheim, 1895) classic insights on the process of refraction (Williams, 2016b) to Vaughan's (Vaughan, 1986) work on the process of uncoupling or leaving relationships. In all of these lines of research, action is seen as carrying a sense of spontaneity that is not reducible to either patterned, schematically determined action on the one hand or to intense deliberation or reflexive assessment on the other (Williams, 2016b). Instead, this research foregrounds the simultaneously active and passive dimensions of action by grounding action in the contexts in which it occurs. In doing so, the antimonies dominant in sociological theorizing-most saliently, structure agency-become more manageable.

Using this research means moving sharply away from calls such as Lizardo et al. (2016) for an unproblematic use of general theoretical frameworks. Seeing action as always being contextualized or agency as always being embedded (Korteweg, 2008, p. 437) shifts research away from definite models and modeling techniques to more situated analysis. Such work may actually be closer to that aimed at by Parsons himself, despite numerous criticisms of his work as being highly abstract (Gerhardt, 2011). Despite such arguable shortcomings, Parsons' research programme-particularly his emphasis on simultaneously analyzing objective and subjective aspects of individual perception and experience-serves as a model for situated, synthetic sociological analysis.

\section{AUTHOR CONTRIBUTIONS}

The author confirms being the sole contributor of this work and approved it for publication.

Bourdieu, P. (1977). Outline of a Theory of Practice. New York: Cambridge University Press.

Bourdieu, P. (1984). Distinction: A Social Critique of the Judgement of Taste. Cambridge, MA: Harvard University Press.

Bourdieu, P. (1990). The Logic of Practice. Stanford: Stanford University Press.

Bourgois, P., and Schonberg, J. (2009). Righteous Dopefiend. Los Angeles, CA: University of California Press.

Burger, T. (1977). Talcott Parsons, the problem of order in society, and the program of an analytical sociology. Am. J. Sociol. 83, 320-339. doi:10.1086/ 226549

Caetano, A. (2015). Defining personal reflexivity: a critical reading of Archer's approach. Eur. J. Soc. Theory 18, 60-75. doi:10.1177/1368431014549684

Cohen, J., Hazelrigg, L. E., and Pope, W. (1975). De-Parsonizing Weber: a critique of Parsons' interpretation of Weber's sociology. Am. Sociol. Rev. 40, 229-241. doi: $10.2307 / 2094347$

Collins, R. (1980). Weber's last theory of capitalism: a systematization. Am. Sociol. Rev. 45, 925-942. doi: 10.2307/2094910

Collins, R. (1986). Weberian Sociological Theory. New York: Cambridge University Press.

Decoteau, C. L. (2016). The reflexive habitus: critical realist and Bourdieusian social action. Eur. J. Soc. Theory 19, 303-321. doi:10.1177/1368431015590700

Dewey, J. (1922). Human Nature and Conduct. New York: Modern Library.

DiMaggio, P. (1997). Culture and cognition. Annu. Rev. Sociol. 23, 263-287. doi:10.1146/annurev.soc.23.1.263

Durkheim, E. (1895). The Rules of Sociological Method. New York: The Free Press. Durkheim, E. (1982). The Rules of Sociological Method. New York: The Free Press. 
Elder-Vass, D. (2010). The Causal Power of Social Structures: Emergence, Structure and Agency. Cambridge, UK: Cambridge University Press.

Garro, L. C. (2000). Remembering what one knows and the construction of the past: a comparison of cultural consensus theory and cultural schema theory. Ethos 28, 275-319. doi:10.1525/eth.2000.28.3.275

Geertz, C. (1973). The Interpretation of Cultures. New York: Basic Books.

Gerhardt, U. (2011). The Social thought of Talcott Parsons: Methodology and American Ethos. London: Routledge.

Goode, W. J. (1960). A theory of role strain. Am. Sociol. Rev. 25, 483-496. doi: $10.2307 / 2092933$

Haidt, J. (2001). The emotional dog and its rational tail: a social intuitionist approach to moral judgment. Psychol. Rev. 108, 814-834. doi:10.1037/0033295X.108.4.814

Haraway, D. (1988). Situated knowledges: the science question in feminism and the privilege of partial perspective. Feminist Stud. 14, 575-599. doi:10.2307/ 3178066

Holmwood, J. (2014). Founding Sociology? Talcott Parsons and the Idea of General Theory. London: Routledge.

Holton, R. J., and Turner, B. S. (1986). Talcott Parsons on Economy and Society. London: Routledge.

Holton, R. J., and Turner, B. S. (2015). Talcott Parsons on Economy and Society. London: Routledge.

Ibarra, H. (1999). Provisional selves: experimenting with image and identity in professional adaptation. Adm. Sci. Q. 44, 764-791. doi:10.2307/2667055

Jerolmack, C., and Khan, S. (2014). Talk is cheap: ethnography and the attitudinal fallacy. Sociol. Methods Res. 43, 178-209. doi:10.1177/0049124114523396

Joas, H. (1996). The Creativity of Action. Chicago: University of Chicago Press.

Joas, H., and Knöbl, W. (2013). War in Social Thought: Hobbes to the Present. Princeton: Princeton University Press.

Korteweg, A. (2008). The Sharia debate in Ontario: gender, Islam, and representations of Muslim women's agency. Gender Soc. 22, 434-454. doi:10.1177/ 0891243208319768

Lamont, M. (1992). Money, Morals, and Manners: The Culture of the French and the American Upper-Middle Class. Chicago: University of Chicago Press.

Lamont, M., Beljean, S., and Clair, M. (2014). What is missing? Cultural processes and causal pathways to inequality. Socio Econ. Rev. 12, 573-608. doi:10.1093/ ser/mwu011

Lareau, A. (2003). Unequal Childhoods: Class, Race, and Family Life. Berkeley: University of California Press.

Lee, C. S., and Munch, P. A. (1979). Fractured Weber: a critique of Parsons' interpretation. Qual. Sociol. 2, 26-41. doi:10.1007/BF02390149

Leschziner, V. (2015). At the Chef's Table: Culinary Creativity in Elite Restaurants. Stanford, CA: Stanford University Press.

Leschziner, V., and Green, A. I. (2013). Thinking about food and sex: deliberate cognition in the routine practices of a field. Sociol. Theory 31, 116-144. doi:10.1177/0735275113489806

Lizardo, O. (2004). The cognitive origins of Bourdieu's habitus. J. Theory Soc. Behav. 34, 375-401. doi:10.1111/j.1468-5914.2004.00255.x

Lizardo, O., Mowry, R., Sepulvado, B., Stoltz, D. S., Taylor, M. A., Van Ness, J., et al. (2016). What are dual process models? Implications for cultural analysis in sociology. Sociol. Theory 34, 287-310. doi:10.1177/0735275116675900

Lizardo, O., and Strand, M. (2010). Skills, toolkits, contexts and institutions: clarifying the relationship between different approaches to cognition in cultural sociology. Poetics 38, 204-227. doi:10.1016/j.poetic.2009.11.003

Martin, J. L. (2011). The Explanation of Social Action. New York: Oxford University Press.

Mead, G. H. (1934). Mind, Self and Society: From the Standpoint of a Social Behaviourist. Chicago, IL: University of Chicago Press.

Mills, C. W. (1959). The Sociological Imagination. New York: Oxford University Press.

Mische, A. (2014). Measure futures in action: projective grammars in the Rio +20 debates. Theory Soc. 43, 437-464. doi:10.1007/s11186-014-9226-3
Morgan, S. L., and Winship, C. (2015). Counterfactuals and Causal Inference: Methods and Principles for Social Research, Second Edition. New York: Cambridge University Press.

Oakes, G. (2003). Max Weber on value rationality and value spheres: critical remarks. J. Classical Sociol. 3, 27-45. doi:10.1177/1468795X03003001693

Parsons, T. (1949). The Structure of Social Action. New York: Free Press.

Parsons, T. (1991). The Social System. London: Routledge.

Pugh, A. J. (2013). What good are interviews for thinking about culture? Demystifying interpretive analysis. Am. J. Cultur. Sociol. 1, 42-68. doi:10.1057/ ajcs.2012.4

Silver, D. (2011). The moodiness of action. Sociol. Theory 29, 199-222. doi:10.1111/ j.1467-9558.2011.01394.x

Strauss, C. (2006). The imaginary. Anthropol. Theory 6, 322-344. doi:10.1177/ 1463499606066891

Swidler, A. (1986). Culture in action: symbols and strategies. Am. Sociol. Rev. 51, 273-286. doi:10.2307/2095521

Swidler, A. (2003). Talk of Love: How Culture Matters. Chicago, IL: University of Chicago Press.

Swidler, A. (2008). Comment on Stephen Vaisey's 'Socrates, skinner, and Aristotle: three ways of thinking about culture in action'. Sociol. Forum 23, 614-618. doi:10.1111/j.1573-7861.2008.00080.x

Turner, B. S. (1991). "Preface," in The Social System, ed. T. Parsons (London: Routledge), xiii-xxx.

Vaisey, S. (2008). Reply to Ann Swidler. Sociol. Forum 23, 619-622. doi:10.1111/j. 1573-7861.2008.00081.x

Vaisey, S. (2009). Motivation and justification: toward a dual-process theory of culture in action. Am. J. Sociol. 114, 1675-1715. doi:10.1086/597179

Vaughan, D. (1986). Uncoupling: Turning Points in Intimate Relationships. New York: Oxford University Press.

Vaughan, D. (1998). Rational choice, situated action, and the social control of organizations: the challenger launch decision. Law Soc. Rev. 32, 23-61. doi: $10.2307 / 827748$

Wacquant, L. J. D. (1990). Exiting roles or exiting role theory? Critical notes on Ebaugh's becoming an ex. Acta Sociol. 33, 397-404. doi:10.1177/ 000169939003300410

Wagner, G., and Zipprian, H. (1986). The problem of reference in Max Weber's theory of causal explanation. Hum. Stud. 9, 21-42. doi:10.1007/BF00142907

Weber, M. (1968). "Basic sociological terms," in Economy and Society: An Outline of Interpretive Sociology, Vol. I, eds G. Roth and C. Wittich (New York: Bedminster Press), 3-62.

Weber, M. (1992). The Protestant Ethic and the Spirit of Capitalism. New York: Routledge.

Western, B. (1996). Vague theory and model uncertainty in macrosociology. Sociol. Methodol. 26, 165-192. doi:10.2307/271022

Williams, L. H. (2016a). "Active intuition: the patterned spontaneity of decisionmaking," in Presented at the 111th Annual Meeting of the American Sociological Association. Available at: http://citation.allacademic.com/meta/p1120670_ index.html

Williams, L. H. (2016b). Talk of pedophilia: the reflexive management of desire. Deviant Behav, 1-13. doi:10.1080/01639625.2016.1257880

Conflict of Interest Statement: The author declares that the research was conducted in the absence of any commercial or financial relationships that could be construed as a potential conflict of interest.

Copyright (C) 2017 Williams. This is an open-access article distributed under the terms of the Creative Commons Attribution License (CC BY). The use, distribution or reproduction in other forums is permitted, provided the original author $(s)$ or licensor are credited and that the original publication in this journal is cited, in accordance with accepted academic practice. No use, distribution or reproduction is permitted which does not comply with these terms. 